Roberto FREGA, Practice, Judgment, and the Challenge of Moral and Political Disagreement

Lexington Books, Plymouth 2012

\title{
Roberto Gronda
}

\section{(2) OpenEdition}

\section{Journals}

Electronic version

URL: http://journals.openedition.org/ejpap/748

DOI: 10.4000/ejpap.748

ISSN: 2036-4091

Publisher

Associazione Pragma

\section{Electronic reference}

Roberto Gronda, «Roberto frega, Practice, Judgment, and the Challenge of Moral and Political Disagreement », European Journal of Pragmatism and American Philosophy [Online], IV-2 | 2012, Online since 24 December 2012, connection on 24 September 2020. URL : http://journals.openedition.org/ ejpap/748 ; DOI : https://doi.org/10.4000/ejpap.748

This text was automatically generated on 24 September 2020.

\section{(c)}

Author retains copyright and grants the European Journal of Pragmatism and American Philosophy right of first publication with the work simultaneously licensed under a Creative Commons AttributionNonCommercial-NoDerivatives 4.0 International License. 


\section{Roberto FREGA, Practice, Judgment, and the Challenge of Moral and Political Disagreement}

Lexington Books, Plymouth 2012

Roberto Gronda

\section{REFERENCES}

Roberto FREGA, Practice, Judgment, and the Challenge of Moral and Political Disagreement, Lexington Books, Plymouth, 2012

1 The book reviewed here, Roberto Frega's Practice, Judgment, and the Challenge of Moral and Political Disagreement, is an important and ambitious book. It is ambitious because it addresses the problems at stake in contemporary philosophical debates without any kind of awkwardness and shyness. Frega believes pragmatism to be a theoretically viable option, and tries to prove its soundness by adopting it as the conceptual framework of a theory of moral objectivity alternative to the ones formulated by analytic philosophers (e.g., Rawls), defenders of communicative reason (Habermas), and critical theorists. It is important precisely because it suggests a new account of objectivity able to overcome the pitfalls that plagued previous attempts to explain the validity of moral and political judgments. Moreover, it is also important because it provides an analysis of the notion of moral objectivity that highlights the main features of originality of the pragmatist tradition, and, in doing so, supplies us with a set of criteria through which it is possible to distinguish among the various lines of thought that coexist in that tradition.

2 The last point is particularly relevant, and it is not by chance that the book begins with a discussion of the similarities and differences between Peirce and Dewey. Pragmatism is becoming a respected voice on moral and political issues, but different interpreters have chosen different aspects of the theory as worthy of being preserved. Different 
images of pragmatism have therefore arisen, and Deweyan and Peircean conceptions of justification, objectivity, pluralism, and so on, have been compared and contrasted. Peirce has been read as advocating a realistic view of objectivity. Objectivity should be defined in terms of truth: there is one way in which things are, and a judgment is true if and only if it adequately represents the way in which things are. On the contrary, Dewey's philosophy has been read as an attempt to get rid of these strong forms of realism in favor of a contextual account of objectivity. According to this view, objectivity depends on the particular point of view from which reality is described.

3 Contrary to interpreters such as Talisse and Misak, who have emphasized the differences between Peirce and Dewey, Frega's approach is much more irenic. While endorsing a theory of objectivity that is largely indebted to Dewey and highly critical of Peirce's scientism, Frega does not introduce any sharp distinction or break between the two versions of pragmatism. Certainly, he recognizes that many aspects of Peirce's theory of rationality are not useful for developing a satisfactory account of the logical processes through which moral and political problems are solved. The Fixation of Beliefor, at least, a certain reading of it - shows that, according to Peirce's epistemology, practical problems cannot be solved by using rational methods of inquiry. It is true that Peirce believes science to be the best method for fixing beliefs, but he also maintains that recourse to science does not hold when we are confronted with practical affairs because, in all these cases, we do not want to know primarily how things are, but how we should act. So, if science is the search for general laws governing reality, and if the discovery of such laws depends on the possibility of bracketing individual preferences, science cannot be of any use to an agent when he is engaged in practical reasoning.

4 However, Frega argues for the validity of Peirce's general account of rationality. From his point of view, Dewey's logic of inquiry completes Peirce's analysis of the structure of reason because it shows how to transform "Peirce's naturalistic insight into a fullfledged naturalistic account of thinking and knowledge" (12). This naturalistic insight is the idea that rationality is a process of belief fixation that has evolved through time, thus selecting the methods and concepts that have proven themselves to be reliable rules of action. Their reliability as rules of action depends on their responsiveness to experience and to arguments: valid beliefs are those that are not contradicted by facts to which the other agents have access and agree with the beliefs held by other participants to the activity (or practice). Reason is therefore conceived as a natural property that characterizes the way in which complex biological organisms experience the world and handle problematic situations. Broadly speaking, it consists in the capacity of an agent to adopt a self-reflective stance towards his actions, and to evaluate the correctness of a certain course of action in terms of its consequences.

5 Frega moves from this point to elaborate his pragmatist account of moral objectivity. Its basic assumption is that everything that has logical validity is not a given but a construct. The two notions which Frega relies on in order to articulate his views on the nature of rationality are the concept of judgment and the idea of normative practice. "Normative practice" is the term chosen by Frega to name the "critical and justificatory activities through which agents defend or criticize given behaviors, opinions, or institutions" (22). It is a concept that does not belong to the pragmatist tradition, but which happily expresses an insight that pragmatists had the merit of formulating with clarity and consistency. This is the idea that normativity cannot be boiled down to an act of following a given rule. If one calls to mind Peirce's distinction 
between the first and the third degree of clearness of a general concept formulated in How to Make Our Ideas Clear, it is easy to understand what Frega means to say. There is a distinction to be drawn between habit as a mechanical repetition of acts and a purposeful course of action which is habitual because it represents a general disposition that is essentially self-corrective. Human activities - Frega's normative practices - are truly human only insofar as they are meaningful, and their being meaningful depends upon the reflective analysis of the consequences that follow from a certain action.

On the contrary, judgment is a technical term in pragmatist vocabulary. As is well known, in his Logic Dewey defines judgment as "the settled outcome of inquiry", and distinguishes judgment from propositions on the basis of their different existential import (LW 12: 123). While propositions are tentative solutions of a problematic situation, judgment is the result of a process through which doubt is settled and new beliefs are established. Frega accepts the theoretical framework provided by Dewey in his Logic, and uses some of the latter's insights to sketch a theory of reasoning powerful enough and broad enough to account not only for scientific research but also for moral and political inquiries.

One of Frega's most important achievements in the book is the clarification of the structure of judgment (in general) and of moral judgment (in particular). As Dewey has shown, judgment is composed of two 'moments': an articulative and a transformative phase. Articulation and transformation are therefore the two operations thanks to which the reconstruction of a problematic situation can be brought about. Through articulation the problem that originates reflection is defined as a problem. Frega is very careful to remark that articulation should not be confused with analysis: contrary to the latter, indeed, articulation does not assume its objects as something which is at the disposal of the agent from the very beginning of the inquiry. The objects that an agent employs in his search for the solution of a certain problem are the outcome of a process of articulative inquiry. Central for the understanding of the peculiarity of this process is the notion of situation. Situation should be taken here in strict Deweyan sense as the "complex existence that is held together in spite of its internal complexity by the fact that it is dominated and characterized throughout by a single quality" (LW 5: 246; quoted at page 53). Following Dewey, Frega argues that the unarticulated whole characterized by a single, unique quality is what can be properly called 'the given.' However, it is a given not in the sense of being an epistemologically simple entity, but rather in the sense of being the ultimate and untranscendable horizon of every possible logical activity. A situation is articulated in thought when objects that satisfy the requirements of inquiry are constructed and, in doing so, pave the way for the solution of the problem.

Once the situation is constructed as problematic and further articulated in the inquiry, an agent can elaborate a plan of action whose raison d'être is to enable him to transform reality according to the goals that he has assumed as his own. Transformation is therefore a logical notion, whose most adequate exemplification is the modern experimental conception of knowledge. Inquiry transforms the existential conditions that gave birth to reflection as well as the system of beliefs of the agent. The two aspects are closely related: if the hypothetical course of action identified in reflection proves itself to be successful, then "thus-far hypothetical belief is stabilized and a new pattern of habits emerges" (56). The notion of transformation crosses the boundaries 
between public and private, objective and subjective, thus revealing the anti-Cartesian attitude of pragmatist epistemology.

This is almost commonsensical knowledge for any pragmatist scholar. Frega has the merit to provide evidence that it is possible to build on these tenets to develop a consistent theory of moral reasoning. Two are the most interesting issues in moral and political philosophy that he takes into account. The first one concerns the definition of the notion of public. Public is a momentum concept for moral and political philosophy because it represents the fact of intersubjectivity. The traditional distinction between public and private relies on the possibility of distinguishing what is done in order to satisfy private, personal desires and what is pursued on behalf of the interest of the community. For a reasoning to be public an agent has to take the point of view of the other members of the community, and, consequently, has to sacrifice what could give him personal gratification. Frega shows with great clearness and force that such an alternative is not necessary. The unquestioned assumption at the basis of all the approaches that acknowledge the validity of the dichotomy between public and private is the idea that both the public and the private are well-formed entities even before entering in relationship, and that they are governed by different and incommensurable 'logics'. Now, if this were true, an individual could not completely realize himself in his community: his realization would always be partial because the adoption of the point of view of the community follows from the renunciation - Frega speaks of "purification" (108) - of some of his desires and pretensions. This would entail a break in the unity of experience, whose epistemological consequences are the split of rationality into a private and a public dimension and, consequently, the destruction of the unity of reason.

The insistence on the constructive power of judgment enables Frega to overcome all these difficulties. According to his convincing diagnosis, Habermas and Rawls - and the traditions that stem from them - have failed to give an adequate account of public reasoning because they have not realized that the community to which an individual refers is not something which has to be accepted and justified, but something which has to be constructed and transformed. The public has often been conceived as a set of beliefs that the private agent has to subscribe or reject. Now, such an intellectualistic approach to the issue of the relationship between the public and the private has generated an unfortunate misunderstanding of the nature of the public. Indeed, it has prevented many from seeing that disagreement - disagreement between an individual and his community as well as between two (or more) individuals belonging to the same community - should not be treated as a logical contradiction that can be overcome if and only if at least one of the competing points of view is shown to rely on false beliefs. In reality, disagreement is a fact of human experience, a fact that is becoming more and more dominant and inclusive as a consequence of the increasing complexity of modernity. The challenge of modern life is to shape conceptual tools for handling the conflicts originated by different and competing ideals and ways of life, not to elaborate conceptual strategies aiming at questioning the legitimacy of a plurality of opinions, beliefs and points of view.

11 It is in this sense that Frega states that the aim of moral and political reflection is not justificatory but transformative: "constitution through inquiry, and not representation through justification, defines the proper core of public reason" (97). Far from being a static entity that has to be taken into account in inquiry, the public is the "outcome of 
the reflective process of inquiry aimed at the identification of the consequences" (102). The point that Frega wants to emphasize is that the notion of the public should be defined in functional terms. The idea of the public arises when an action is conceived as producing consequences that are neither natural effects nor epistemic implications but consequences having a social impact. More clearly stated, "[ $t]$ he concept of public refers only to those consequences (intended or unintended) that affect people beyond those directly involved in the action" (101). So, a particular public is brought into being when agents engaged in a common enterprise realize that the consequences of their actions have relevant effects on other people.

The functional definition of the public shows the theoretical fertility of the pragmatist conception of rationality of inquiry. Indeed, the latter provides a general framework in which it is possible to formulate the problems of moral and political philosophy in a way that makes it easier to find their solution. Moral and political issues, on the one hand, and the public - conceived as that community of people who share an interest in the consequences of a certain group of actions -, on the other hand, are mutually determined and constructed in the process of inquiry through which a problematic situation is solved. The public, the issues to be dealt with in a political and moral inquiry, the interests and aims of the agents engaged in a public activity acquire significance only as a consequence of a process of construction of their meaning - a process that consists in discovering the possible consequences of an action. For this reason, I am not completely persuaded of what Frega says about the public being "the outcome of a political quest" (104). I fully agree with Frega that the passage to a transformative conception of public reasoning grounded on a issue-centered approach to politics determines a dynamic conception of the public. However, since the public originates from a problematic situation, according to a pragmatist epistemology it should disappear when the problem is solved. As is evident, if this is correct the public cannot be the outcome of a political and moral inquiry, but should be treated as an extremely refined tool that is constructed and used in inquiry but has no logical validity outside of it. Here Frega seems to relapse into a structural and anti-pragmatist way of intending the concept of the public, which relies on a misunderstanding of the logical nature of the conceptual instruments employed in reasoning.

Leaving aside the last critical observation, it is important to note that Frega's notion of the public is extremely interesting for another order of reasons. As has been remarked above, it follows directly from the rejection of the classical distinction between the public and the private that the former should not be treated as the result of a process of purification of personal interests, but rather as the 'locus' where agents can find their most complete realization. It is very likely that some sort of Hegelian suggestion about the relation between the particular and the universal is at work here. In any case, the point that deserves attention is not historical but theoretical: it has to do with the idea that an internal relationship links together the public and public reasoning. The polemic target that Frega has in mind here is the way critical theorists conceive the structure of the public. According to them, the public is a field of conflicting forces in which there is no other rule than power: the dominating position is not the one that is (more) correct or (more) fair, but the one which better represents the interests of the majority. According to this view, therefore, it does not make any sense to search for a logic of public reasoning because reasoning is at best a way of concealing the real nature of the public, that is, the instable equilibrium of conflicting interests. 
14 As Frega explicitly acknowledges, the solution he advocates is a third way outside the dichotomy between accepting the classical distinction of "public" and "private" ways of conducting an inquiry and denying logical validity to public reasoning (115). Following Dewey, Frega wants to stress the fact that the public represents a possible way in which agents tackle the problems that are caused by their actions, and in doing so they can find a possible realization of their interests and desires. In order to achieve this goal he relies on the notion of 'expression' or 'expressive inquiry.' This is the second important contribution that Frega gives to the theory of moral reasoning.

Expressive inquiry is the idea that moral reasoning has a strong articulative power, and that the process of articulation consists of a process of expression of the self. As has been said above, every inquiry has an articulative moment: this is the phase in which a situation is constructed as a problematic situation. In the case of moral inquiry, what has to be articulated is not only the external situation but also the net of beliefs that define the character of the moral agent. Therefore, moral judgment is more complicated than scientific judgment because the former cannot be concerned exclusively with the articulation of external conditions. Moral action is an action in which what is at stake is the kind of person that the agent wants to be. Consequently, moral judgment has to be expressive of the self, both in the sense of taking into account the beliefs of the agent about what is right to do and to be and in the sense of being the factor that helps the self develop and express its potentialities. It is for this reason that Frega says that moral inquiry encompasses "a broad array of thinking activity": not only the reflection on the possible consequences of an action, but also self-analysis, the comparison of the situation with the agent's desires, criteria, and expectations, the making of hypotheses about the way to become the kind of person that one wants to be (80).

It should be evident now that Frega's expressivism has nothing to do with the versions of expressivism elaborated by analytic philosophers. Indeed, far from supporting a noncognitivist interpretation of morality, Frega's expressivism denotes a particular quality of moral reasoning and, consequently, of moral rationality. At the same time, however, the insistence on the concept of expression makes it possible for Frega to avoid the strong cognitivist implications of the thesis that inquiry is the best method that an agent has to fix his beliefs. Again, Frega's aim is to find a via media between two equally unsatisfactory alternatives.

17 This point stands out clearly if one takes into consideration Frega's discussion of relativism. According to Frega, relativism should not be considered as a problem haunting moral reflection but as a fact constitutive of human experience (132). It is a fact that there is a plurality of perspectives since it is a fact that human beings interpret reality in different ways according to their interests, desires, and beliefs. Consequently, to criticize relativism at this level is nonsensical because it would amount to denying an essential aspect of (moral) reality. Relativism can be criticized only as a philosophical theory that challenges not the fact of disagreement, but the very possibility of moral agreement.

18 This assumption has important bearings on the evaluation of theoretical tenability of relativism. First of all, as a consequence of the shift of attention from relativism as a problem to relativism as a fact of experience Frega can formulate the issue at stake in the debate between relativists and realists in a radically new way. The traditional conception of relativism is grounded in two independent theses: "the claim that 
different views on any given issue may be incompatible and yet coexist" and the thesis that that claim entails "the impossibility to attain context-independent normative standards" (137). According to this view, the fact of relativism (de facto level) implies a distrust in the possibility of achieving an agreement founded on rational norms (de jure level). This kind of relativism - which Frega labels as 'dogmatic' - brings about an equally dogmatic form of realism which assumes that both de facto and de jure relativisms are false. Dogmatic anti-relativism is an account of moral objectivity which holds a) that it is always possible to "reach an uncontroversial solution within a reasonable (not indefinite) time" if the inquiry is not distorted by personal interests; and b) that "[t]he outcome of any well-conducted inquiry is independent of the inquiring agents' epistemic conditions" (138).

19 Frega convincingly argues that a relativist is not forced to accept both the theses mentioned above. If he holds the first - the idea that pluralism is not contradictory and drops the second - the idea that the fact of pluralism does not support moral objectivity - he can endorse a kind of relativism which is epistemologically less vulnerable to anti-relativist criticisms. It is less vulnerable not because it concedes something that an anti-relativist account of objectivity cannot deny - the possibility of objectivity -, but because it dramatically alters the epistemological framework that makes the very contraposition between relativism and anti-relativism possible.

This is the ultimate meaning of the expressivist turn that Frega gives to the theory of moral reasoning. Moral inquiry should not be conceived as the search for a representation of what is morally true, but rather as the search for a satisfactory compromise among the different interests, desires, and beliefs of the members of a community. Stated in Kantian terms, it can be said that, according to Frega, the notion of truth is not the principle of moral judgments. Frega's contention is that if one tries to understand moral inquiry as a type of reasoning relying on the principle of noncontradiction and aiming at achieving a form of objectivity similar to the one achieved in science he is easily led to misconceive the role that moral reflection plays in our life. What we want from moral objectivity is a method for fixing beliefs: "objectivity," Frega writes, "names the capacity of these regulations [habits] to successfully respond to challenges" (158). The objectivity that is the goal of moral reasoning is the construction of a new way of life that can be judged fair and correct by all its participants since it is the expression and articulation of their points of views. It is for this reason that disagreement is so important for Frega: it is the fact that the plurality of perspectives on what is good cannot be overcome on an epistemological level - that is, it is not possible to ascertain the true opinion on the conduct of life because all the different perspectives represent legitimate ways of conceiving moral reality - that grounds the validity of moral constructivism. In other words, truth cannot be the key to understanding morality because in moral inquiry agents "do not aim first at 'getting things right' but rather at 'getting things done"' (162).

The last remark brings us to the core of Frega's constructivism. Keeping in mind Dewey's definition of object as what is "produced and ordered in settled form by means of inquiry," it is not difficult to see how Frega can defuse the problems that motivate the traditional rejection of relativism (LW 12: 122). Constructivism means that human beings have to find a method to solve the difficulties that arise from social, political, economical inequalities, and that the validity of the solution they produced is warranted by its effectiveness in constructing a satisfactory way of life. Consequently, 
even without embracing a cognitivist conception of objectivity, Frega's constructivism is not exposed to the risk of relativism because a morally objective belief is the one that shows in practice what is its meaning and what is its epistemic value.

It is for this reason that Frega puts such a great emphasis on the notion of practice, in general, and of normative practice, in particular. The latter is the cornerstone of Frega's expressivism since it is the theoretical device that enables him to account for moral objectivity in pragmatic terms. However, there is a price to be paid for this choice. Indeed, the primacy of practice over theory implies a dramatic restriction of the creativity of reason which, in turn, implies a restriction of the transformative power of inquiry. Frega accepts this conclusion. He speaks of an "inescapability of the context of practice" to refer to the fact that every tool constructed in inquiry - no matter how refined and sophisticated it could be - has to be brought back to the particular context from which it arises and to be used to solve the problem that has called up moral reflection (139). More clearly stated, the point that Frega wants to emphasize is that normative practices set limits to the acts of reasoning that take those very normative practices as their subject-matter.

However strange it may seem, this description catches an important element of moral inquiry. As is well known, one of the most important traits of moral reasoning is the search for moral justifications. To use Frega's own words, justification is "the activity through which an agent proffers arguments intended to show belief, decision, or action to be legitimate" (179). Now, an agent undertakes a justificatory activity when some of his moral and political beliefs are put into question by another person. This statement is not as trivial as it may seem at a first glance. Traditionally, the search for moral justification has been conceived as an armchair activity made by philosophers, "an intellectual undertaking whose relevance does not depend on its effectiveness in answering real doubts such as they emerge in social life" (179). According to this view, an inquirer searches for a justification of, say, democracy because he has a purely intellectual interest in it. Against this intellectualistic account of justification, Frega calls the attention to the nature of the disagreement that has to be resolved by moral judgment: "the source of disagreement," he writes, "must be living" (179). This does not mean simply that the agents have a practical interest in solving that problem. It means, first and foremost, that they cannot escape from the particular conditions in which they are immersed.

It is important to understand the epistemic consequences of this strong form of contextualism. The epistemological primacy of existing normative practices implies that the argumentative strategies that are available to be used to reach agreement among the members of a community are limited to their actual 'knowledge'. "Each practice," Frega observes, "is spatio-temporally determined, in order to limit its reference to the conditions that define the possibilities of inquiry in a given place and time" (172). It follows therefore that if the critics of a certain normative practice - for instance, our democratic way of living and handling conflicts - are not disposed to accept the entire framework of that form of life, it is not possible for its members to provide a justification of its legitimacy. There is an important distinction that has to be drawn, Frega warns us, between internal and external justification. External justification is a type of justification that holds universally for all rational persons. This kind of justification - whose possibility is at the basis of the successes of scientific inquiry - cannot be achieved in moral reasoning because in this case it is impossible to 
'bracket' the differences among individuals. The differences of beliefs, of values, of interests, of desires are the source of disagreement, and to say that to overcome disagreement one should not pay attention to them is like saying that moral disagreement is not worthy of attention. Consequently, the only justification that can be provided for the legitimacy of a normative practice is internal. More clearly stated, since moral inquiry is the construction of a new normative practice in which the members of a community can find a satisfactory expression of their perspectives on what is morally relevant, the different points of view must not be irreconcilable. Indeed, justifications can be effective if and only if the individuals who challenge the legitimacy of a certain normative practice share a common framework. Frega is clear on this point: "it is very unlikely that someone who has exited democratic practice (or has never taken part in it) will come back into it (or will join it) on the basis of an argument demonstrating that people should be democratic so that their beliefs may be more justified." And he adds: "[w]ith the Schmittian there is no common ground, no shared practice on which to build a common framework" (185). Incidentally said, the idea that moral justification must be internal is just another way of formulating the fundamental pragmatist insight that doubt cannot be universal: if one doubts of everything the conclusion that has to be drawn is not that nothing is certain, but that his is not a real doubt. The problematic situation must have in itself the possibility of its solution.

In conclusion, the point of Frega's argument is that justification is a practice which is effective only within the boundaries of a particular community of members sharing common ideas and opinions. Disagreement on a specific moral issue is possible only because there is a more substantial agreement on the essential structure of moral reality. Such a more substantial agreement that makes disagreement possible is the result of common experiences, of common interests, of common problems and, in particular, of a common education. It is rather surprising that Frega does not use the language and the basic ideas of virtue epistemology and virtue ethics - in particular, the concepts of habit and virtue. I believe that if Frega had addressed the issue of the relationship between reason and will, his defense of constructivism and contextualism would have been much clearer and sounder. In the last analysis, indeed, the truth of Frega's contextualism of normative practices is a consequence of the fact that normative practices do not depend on reason for their legitimation. However, this lack of conceptual resources does not affect the soundness of the conclusions that Frega draws from the idea of a primacy of practice over theory. Frega convincingly argues that normative practices have legitimation not because it is always possible to provide an universal justification of their validity, but because of the practical consequences they engender (184). The legitimacy of democracy relies on the fact that it is a "solution that has evolved over time, overcoming the social and political challenges that Western society have faced over several centuries," a solution that continues to work well in a society that is growing more and more complicated and conflictual (213).

This is the root of Frega's pragmatist and anti-intellectualist philosophy. Consequently, the rigorous exposition and clarification of its fundamental concepts and principles is the most important achievement of the book. Now, to be clear, I believe that it is impossible to overestimate the importance of this approach to philosophical questions for the future of pragmatism. Frega's constructivist theory of rationality leads to an empiricization of philosophical reflection that goes hand in hand with a substantial redefinition of the language of philosophy. According to this view, philosophers should 
start conceiving their professional activity as a contribution to the amelioration of existing normative practices, and not as a purely intellectual effort devoted to find an unshakable basis for our beliefs. These are conclusions that Frega is certainly willing to endorse since he is deeply committed to fostering the mutual interchange of ideas between philosophy and social sciences. But these are conclusions that every scholar interested in pragmatism should be, if not willing to endorse, at least willing to pay due attention to because they represent the most ambitious attempt to give a definition of theoretical concepts in terms of their practical effects.

However, I think it is important to warn against a possible misunderstanding - a misunderstanding from which Frega's work, too, seems sometimes to suffer. As has been remarked above, to insist on the primacy of practice over theory is certainly correct, but it should not lead to deny the autonomy of theory from practice. Theory can be defined operationally as that ensemble of normative practices whose function is to construct tools that help agents to be more effective in handling problems encountered in life. Now, history of technology has shown that the success of these practices depends on the possibility of reaching higher and higher levels of abstraction. Tools created to handle a practical problem become the subject-matter of a higher science. Consequently, new and more refined tools are constructed that enable scientists to tackle those problems that affect the application of the "original" tools to the specific situations they were intended to handle. This is a platitude, but this platitude entails an important corollary. Indeed, it follows from it that in some particular cases it may be useful to adopt an extremely general attitude toward morality. In some cases, for instance, it may be useful to inquire into the formal structure of moral justification or to discuss what counts as morally significant. This because there is no agreement among discussants on these points. As is evident, formal analyses of this kind do not have immediate practical bearings. So, if the ultimate criterion of validity of moral reasoning is its effectiveness in transforming and meliorating existing normative practices, it would be difficult to accept them as correct forms of moral inquiry even though it would be equally difficult to question that they are legitimate moves in the "game of morality." As the increasing complexity of human social systems has brought about new needs and demands, it has brought about also a plurality of autonomous contexts of inquiry. This plurality is a fact of scientific experience, and has therefore to be acknowledged in its own right. But if this is true, then the emphasis on the primacy of practice over theory risks to be a too restrictive criterion.

I do not want to say that Frega's pragmatism of normative practices programmatically rules out the possibility of recognizing a certain degree of autonomy to the various levels of reflection. Rather the contrary, I do believe that this insight can be easily accommodated within the framework of his constructivism. It is even possible that Frega would consider the problems of defining the nature of moral justification and of clarifying what is morally significant as scientific (theoretical) rather than moral issues. Nonetheless, I think that his insistence on practice, his criticism of external justification, his suspiciousness of what he calls "an understanding of human experience [...] dominated by a hyper-rational conception of human reason" may lead to a form of anti-intellectualism that sacrifices much that should be preserved (110-2). And this is a risk that does not concern only Frega's masterful investigations of moral inquiry, but the entire pragmatist movement. 


\section{AUTHORS}

\section{ROBERTO GRONDA}

Scuola Normale Superiore di Pisa

roberto.gronda[at]sns.it 